\title{
Investigation on Hull Hydrodynamics with Different Draughts for 470 Class Yacht ${ }^{+}$
}

\author{
Yong Ma ${ }^{1, *}$, Shijie Lin 1,2, Yangying He ${ }^{1}$, Xiaoshan Lei ${ }^{1,2}$ and Song Zhang 1,2 \\ 1 School of Sports Engineering and Information Technology, Key Laboratory of Sports Engineering of \\ General Administration of Sport of China, Wuhan Sports University, Wuhan 430079, China; \\ shijielin900819@foxmail.com (S.L.); yangyinghe0915@foxmail.com (Y.H.); leixiaoshan1010@126.com (X.L.); \\ songzhang0830@foxmail.com (S.Z.) \\ 2 Graduate School of Wuhan Sports University, Wuhan 430079, China \\ * Correspondence: small_ma@163.com; Tel.: +86-27-8719-1061 \\ + Presented at the 12th Conference of the International Sports Engineering Association, Brisbane, \\ Queensland, Australia, 26-29 March 2018.
}

Published: 22 February 2018

\begin{abstract}
Class 470 yacht attracts more and more attention at the World Championships. The hull hydrodynamics is important for winning the games. Hull draughts influence ship maneuverability, seakeeping, rapidity and stability. Numerical simulation by solving RANS equations is used to hull hydrodynamics with different draughts for the 470 Class yacht. Turbulence model is (SST) k- $\omega$. The results show that wave resistance, viscous pressure resistance, friction resistance with the Froude number is different when the hull draught is different. According to the results about hull hydrodynamics with different draughts and the aerodynamics of the sail wing, the resistance performance of the hull is good when the hull draft for 470 Class yacht is within a relatively reasonable zone. This study on resistance performance of the hull provides a theoretical reference for coaches to talent selection of sailing athletes, weight distribution of athletes, estimate the sailing route and maneuverability of the sailing boat.
\end{abstract}

Keywords: CFD; yacht; hull; draughts; Froude number; wave resistance

\section{Introduction}

The sailing of class 470 is a double boat racing project which follows the certain rules of the game within a certain zone of water racing. The class 470 yacht is getting more and more attention in the world championships and the Olympic Games. The key to winning the game is to master sailing characteristics, select the optimal route and optimize the selection of athletes [1]. The depth of the hull draft has serious influence on maneuverability of the sailing, wave resistance of the sailing, rapidity of the sailing, stability of the sailing and distribution of trim stress on the hull [2]. The depth of the hull draft has a significance of competitive strategy to the selection and collocation of athletes' weight.

With the impressive promotion of the speed and capacity of computers, the continuous improvement of the numerical computation method, the accuracy of making a prediction about the hull hydrodynamic performance of the sailing ship which is based on the numerical computation method is higher and higher [3-5]. Parolini et al. (2005) [1] made a research on the "America's cup" sailing ship of different states by solving the Reynolds-averaged Navier-Stokes (RANS) equations and the result of this research made a contribution for the title of alinghi in the America's cup. Mylonas et al. (2012) [6] made a research on the hydrodynamic performance of the America's cup sailing ship, which showed that simulated result of the large eddy simulation (LES) method and the detached eddy simulation method is smaller than the test results, which can more accurately simulate 
the near wall flow by using the LES model. Viola et al. (2014) [2] conducted a test of the optimal location of athletes from the stern on the ship model of 1:4 by the dragging pool at China in recent years.

At present, Chinese research projects about sailing mainly concentrate in the study of aerodynamic performance of sail wing [7], the study about the hull hydrodynamic performance of the sailing hull has just started. This research conducted a study on the hull hydrodynamic performance of the class 470 yacht of different depths of the hull draft based on computational fluid dynamics (CFD) methods, which provides a basis for sailing athletes manipulating the sailing boat, the collocation of athletes' weight and selecting athletes and sports equipment.

\section{Methods of Analysis}

\subsection{Numerical Model and Conditions}

The numerical model computed was the Olympic Class 470 yacht, which aimed to investigate the flow field around the hull. The principal dimension of the hull length is $4.7 \mathrm{~m}$ and the width is $1.68 \mathrm{~m}$. The numerical model is obtained by surveying the competition yacht and drawing in CAD \& ANSYS. This experiment was modelled with CFD using a hexahedral grid built with ANSYS ICEM CFD (version 15.0) and solved with ANSYS Fluent (version 15.0) [8]. The total hexahedral grid element number is more than 4 million. The grid around hull and free surface special encryption and the grid allowed $80<\mathrm{y}^{+}<200$ on the hull side, where the boundary layer is attached. Investigation on hull hydrodynamics with six different draughts were performed when displacement is $230 \mathrm{~kg}$, $240 \mathrm{~kg}, 250 \mathrm{~kg}, 260 \mathrm{~kg}, 270 \mathrm{~kg}, 280 \mathrm{~kg}$ for 470 Class yacht respectively.

The transient incompressible RANS equations for Newtonian fluids were solved with a pressure based solver and a finite volume approach is one of the main methods to calculate the liquid-phase flow. The control equation based on continuity equation and RANS in this study. The flow field around the 470 Class yacht is incompressible liquid. Continuity equation and momentum equation in the Cartesian coordinate system is define as follows:

Continuity equation:

$$
\frac{\partial u_{i}}{\partial x_{i}}=0
$$

Momentum conservation equation:

$$
\frac{\partial\left(u_{i} u_{j}\right)}{\partial x_{j}}=-\frac{1}{\rho} \frac{\partial p}{\partial x_{i}}+\frac{\partial}{\partial x_{j}}\left[v_{t}\left(\frac{\partial u_{i}}{\partial x_{j}}+\frac{\partial u_{j}}{\partial x_{i}}\right)\right]-\frac{\partial\left(\overline{u_{i}^{\prime} u_{j}^{\prime}}\right)}{\partial x_{j}}+B_{i}
$$

where $u_{i}$ is average speed and $u_{i}^{\prime}$ is fluctuation velocity $(i=1,2,3), \rho$ is the fluid density, $t$ is time, $v_{t}$ is the kinetic viscosity of the fluid, $B_{i}$ is body force and $\overline{u_{i}^{i} u_{j}^{\prime}}$ is turbulent influence.

\subsection{Boundary Conditions}

The related boundary conditions are the key to simulate the flow field around the 470 Class yacht accurately. In this research, the type of inlet is the velocity-inlet that selected average speed of the Yacht $(\mathrm{V}=6 \mathrm{~m} / \mathrm{s}, 11.67 \mathrm{Kn})$, the type of outlet is the pressure-outlet that converges rapidly, the hull wall type is the wall that shear condition is no slip [9].

\subsection{Solution Setup}

The VOF method unite developed double model method to do investigation on hull hydrodynamics with different draughts for the 470 Class yacht. Turbulence was modelled with the SST K- $\omega$ turbulence model. A SIMPLEC scheme was used to couple velocity and pressure. Second order accuracy discretization algorithms were used in the transient investigation because third order accuracy algorithms showed difficulty converging. 


\section{Numerical Results and Analysis}

\subsection{Draught Resistance Coefficients Changing with the Froude Number (Fr)}

Froude number $\mathrm{Fr}$ is one of the important coefficients of similarity criterion when simulated with the free surface liquid flow. The simulation model of 1:1 real Olympic Class 470 yacht. $\mathrm{Fr}$ and draft depth can be reference to the relationship between volume displacement definitions:

$$
F r=\frac{\nabla}{(\sqrt{g} \times \sqrt[6]{\nabla})}
$$

$\nabla$ is the displacement of different drafts. With draft depth increases, $F r$ reduces gradually. While $\mathrm{Fr}$ is greater than 1 in the total 6 conditions with displacement range from $230 \mathrm{~kg}$ to $280 \mathrm{~kg}$ and inertia force plays the leading role.

From Figure 1, drag coefficient $\left(C_{d}\right)$ and $F r$ are the nonlinear relationship. At a constant speed, with the $F r$ decreases, namely the draft depth increases, hull resistance coefficient first decreases slightly, then gradually increases and decreases at last.

The minimum resistance coefficient occurs at $F r=2.43$ and the maximum resistance coefficient happens at $F r=2.383$. When equipment is selected in the actual competition, from $230 \mathrm{~kg}$ to $280 \mathrm{~kg}$. $240 \mathrm{~kg}$ displacement is the preference selection from this study.

From the relationship between $C_{d}$ and $F r$, we can conclude that the simulation calculation results have a significance reference on choosing athletes and sports equipment.

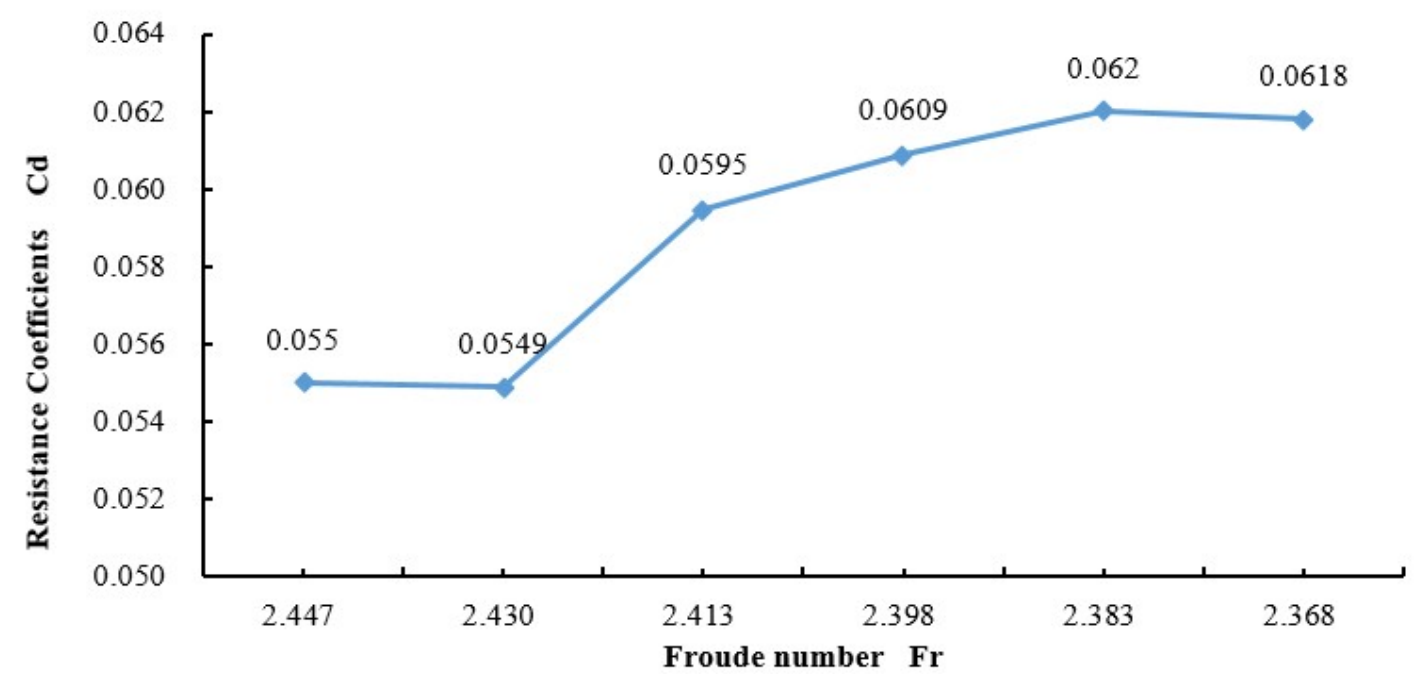

Figure 1. Draught resistance coefficients $C_{d}$ changing with the Froude number $F r$.

\subsection{Resistance Analysis}

Hull resistance is the main factors influencing the sailing ship speed, the hull side force and are almost zero when ship sails on the positive direction. The total resistance $R_{t}$ consists of frictional resistance $R_{f}$, viscous pressure resistance $R_{p v}$ and wave resistance $R_{w}$.

By considering the free surface wave resistance combining the developed double model method without wave resistance, rough estimate of the wave-making resistance are extracted, as shown in Table 1.

The 470 sailing in nearly 12 knots, namely $\mathrm{V}=6 \mathrm{~m} / \mathrm{s}$, wave resistance $R_{w}$ in total resistance $R_{t}$ components accounted for about $46 \%$, viscous pressure resistance $R_{p v}$ is slightly small, but they should not be ignored.

As shown in Figure 2, with the increase of the draft, $F r$ decreases, pressure drag $R_{p}$ gradually becomes bigger, viscous pressure resistance $R_{p v}$ has little change, wave resistance $R_{w}$ gradually 
increases. Along with $F r$, hull wet area is gradually increasing, besides, hull frictional resistance $R_{f}$ has a little change in cause of the increased wave, but tends to increase.

In general, along with the draft depth increases, the $F r$ number decreases, wave resistance $R_{w}$ and pressure drag $R_{p}$ gradually increase, frictional resistance $R_{f}$ slightly increases and viscous pressure resistance $R_{p}$ shows little change.

The above analysis on working conditions of 6 kinds of the 470 Class yacht can conclude that to some extent draft had significant effect on the change of wave, as s shown in Figures 3 and 4. So, the coaches and athletes should put great attention to the material weight factors. At the same time, it can offer some science and technical guidance for winning the game for the sailboat displacement can be adjust within the game rules.

Table 1. Numerical results of the Olympic Class 470 yacht.

\begin{tabular}{ccccccc}
\hline The Project of the Olympic Class 470 Yacht & \multicolumn{7}{c}{ Numerical Results } \\
\hline Different draughts $(\mathrm{m})$ & 0.1742 & 0.1774 & 0.1804 & 0.1834 & 0.1963 & 0.1892 \\
Hull displacement $(\mathrm{kg})$ & 230 & 240 & 250 & 260 & 270 & 280 \\
Froude number $(F r)$ & 2.447 & 2.43 & 2.413 & 2.398 & 2.383 & 2.368 \\
Pressure drag coefficients $\left(C_{p}\right)$ & 0.0303 & 0.0318 & 0.0339 & 0.0352 & 0.0362 & 0.0373 \\
Frictional resistance coefficients $\left(C_{f}\right)$ & 0.0252 & 0.0232 & 0.0256 & 0.0257 & 0.0258 & 0.0245 \\
Viscous pressure resistance coefficients $\left(C_{p v}\right)$ & 0.0066 & 0.0066 & 0.0071 & 0.0068 & 0.0074 & 0.0066 \\
Wave resistance coefficients $\left(C_{w}\right)$ & 0.0237 & 0.0252 & 0.0268 & 0.0284 & 0.0288 & 0.0307 \\
$C_{w} / C_{d}$ & $42.7 \%$ & $45.8 \%$ & $45 \%$ & $46.6 \%$ & $46.4 \%$ & $49.7 \%$ \\
\hline
\end{tabular}

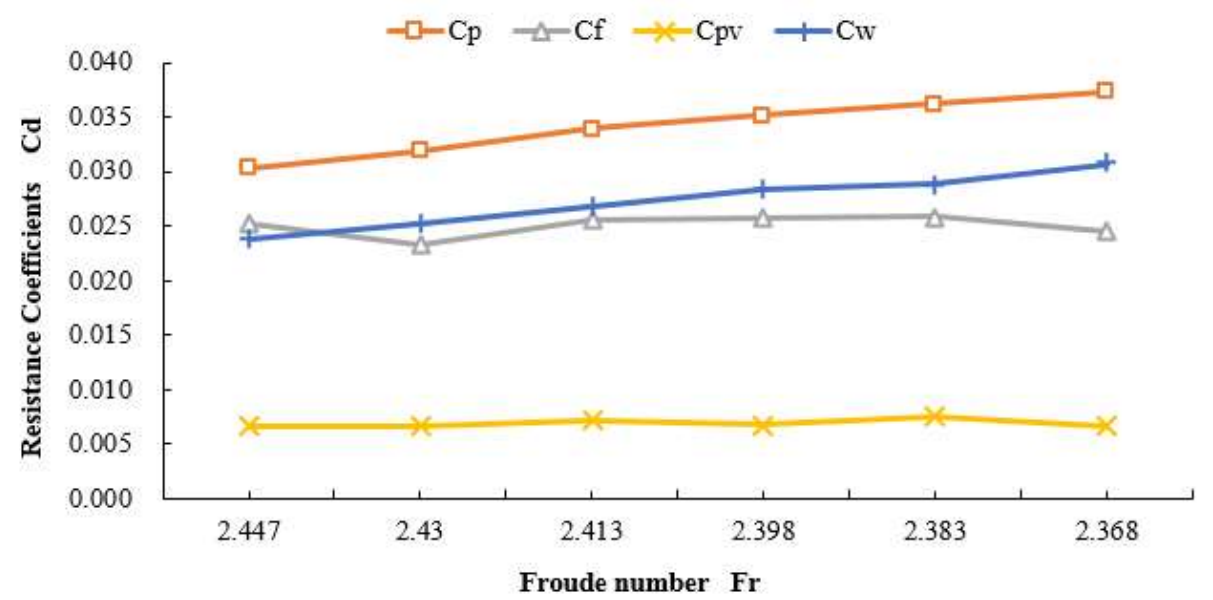

Figure 2. Resistance Coefficients changing with the Froude number Fr.

$\mathbf{a}$

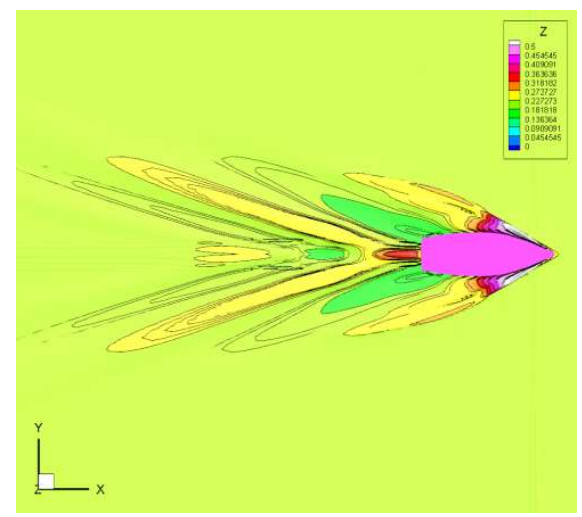

b

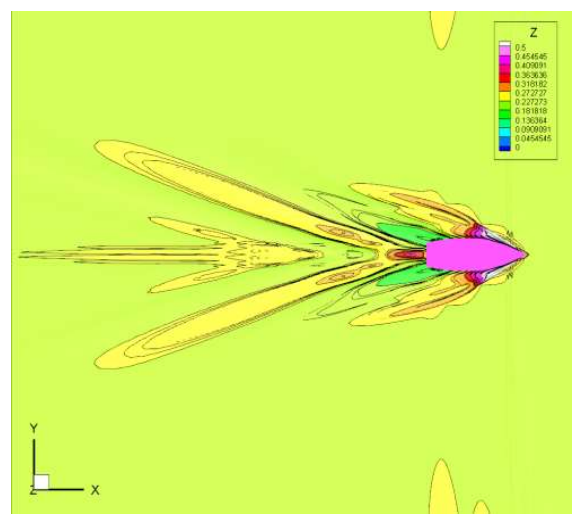

Figure 3. Numerical wave results of the free surface with displacement of the hull (a) $230 \mathrm{~kg}$ and (b) $270 \mathrm{~kg}$. 
a

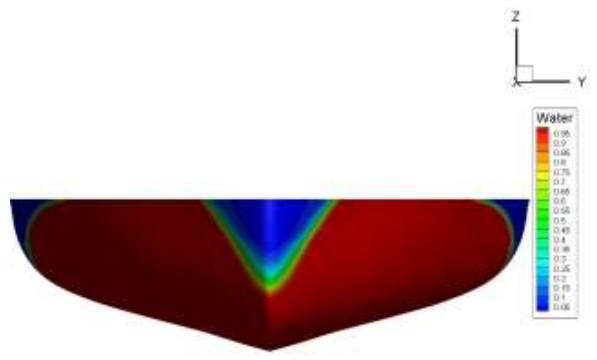

c

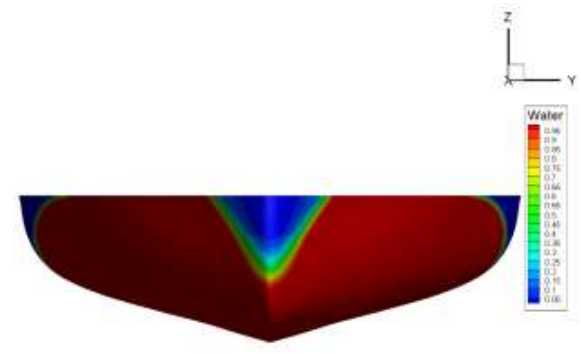

e

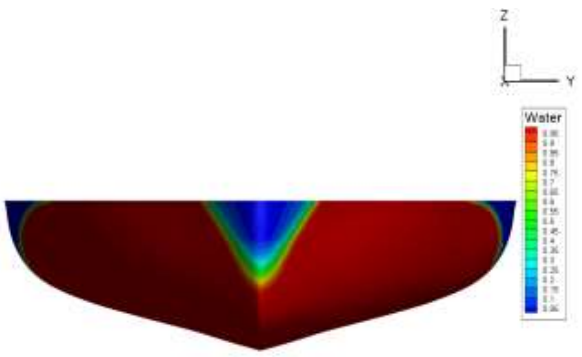

b

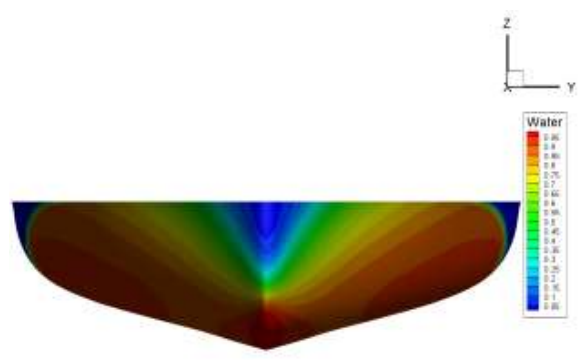

d

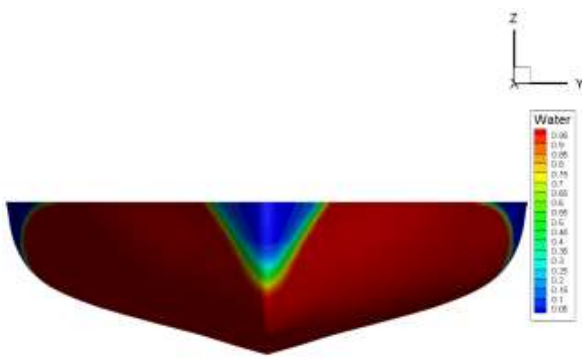

f

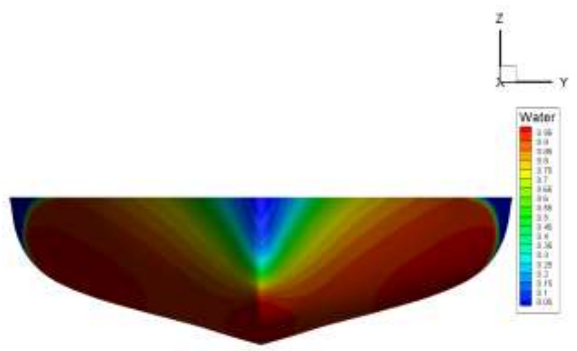

Figure 4. Numerical wave results of the Olympic Class 470 yacht with different hull displacements (a) $230 \mathrm{~kg}$, (b) $240 \mathrm{~kg}$, (c) $250 \mathrm{~kg}$, (d) $260 \mathrm{~kg}$, (e) $270 \mathrm{~kg}$ and (f) $280 \mathrm{~kg}$.

\section{Conclusions}

This paper stimulated the hydrodynamic performance of a Class 470 yacht in different draughts by the SST K- $\omega$ turbulence model, the VOF method unites the developed double model method. This experiment was modelled with CFD using a hexahedral grid built with ANSYS ICEM CFD and solved with ANSYS Fluent. The simulation results of different hull draughts show that different draughts play a major role on the performance of yacht sailing. The draught of the hull can affect the component of wave resistance in the total resistance significantly, and bring just a little influence on the components of friction resistance and viscous pressure resistance. In the analysis of the relationship between $\mathrm{Fr}$ and $C_{d}$, we found that the lowest resistance coefficient appears when $\mathrm{Fr}=$ 2.43 , and highest when $\mathrm{Fr}=2.383$. As for the guidance for select athletes, the established scientific results indicate that the athletes combination with $240 \mathrm{~kg}$ displacement can be a good choose in a match. This study found a relatively reasonable droughts zone exists in the class 470 yacht. Studying properties of draughts resistance of the class 470 hull can offer theoretical reference for coaches to select athletes, scientifically match weights of athletes in a match, for route strategy adjustment and athletes to have a quantitative control of the yacht. 
Acknowledgments: This study was partially supported by National Natural Science Foundation of China (Grant No. 51679183, 51279154), the Fok Ying-Tong Education Foundation for Young Teachers in the Higher Education Institutions of China (Grant No. 141112), Hubei Natural Science Funds for Distinguished Young Scholar (Grant No. 2013CFA038), Outstanding Youth Science and Technology Innovation Team Foundation of the Colleges and Universities of Hubei Province (Grant No. T201320), the East Lake Scholars Sponsorship Program of Wuhan Sports University and Hubei Dominant Characteristic Discipline Group.

Conflicts of Interest: The authors declare no conflict of interest.

\section{References}

1. Parolini, N.; Quarteroni, A. Mathematical Models and Numerical Simulations for the America's Cup. Comput. Meth. Appl. Mech. Eng. 2005, 194, 1001-1026.

2. Viola, I.M.; Enlander, J.; Adamson, H. Trim Effect on the Resistance of Sailing Planning Hulls. Ocean Eng. 2014, 88, 187-193.

3. Akimoto, H.; Miyata, H. Finite-volume Simulation Method to Predict the Performance of a Sailing boat. J. Mar. Sci. Technol. 2002, 7, 31-42.

4. Böhm, C.; Graf, K. Advancements in Free Surface RANSE Simulations for Sailing Yacht Applications. Ocean Eng. 2014, 90, 11-20.

5. Campbell, I.; Owen, M.; Provinciali, G. Dagger-board Evaluation for an IMOCA 60 Yacht. Ocean Eng. 2014, 90, 2-10.

6. Mylonas, D.; Sayer, P. The Hydrodynamic Flow around a Yacht Keel Based on LES and DES. Ocean Eng. 2012, 46, 18-32.

7. Ma, Y.; Tang, Y.H.; West, N.; Zhang, Z.Y.; Lin, S.J.; Zheng, Q.Z. Numerical Investigation on Trimming of a Single Sail in a Regatta. Sports Eng. 2016, 19, 81-90.

8. Zheng, Q.Z.; Ma, Y.; Zhang, Z.Y.; Lin, S.J.; Tang, J.T.; Liu, L. Experimental Research of Sailing Hull Shape Measurement in Olympic Games. J. Sports Adult Educ. 2015, 31, 76-80.

9. Huetz, L.; Guillerm, P.E. Database Building and Statistical Methods to Predict Sailing Yacht Hydrodynamics. Ocean Eng. 2014, 90, 21-33.

(C) 2018 by the authors; Licensee MDPI, Basel, Switzerland. This article is an open access article distributed under the terms and conditions of the Creative Commons Attribution (CC BY) license (http://creativecommons.org/licenses/by/4.0/). 